\title{
CAPÍTULO 18. DIAGNÓSTICO DA AMBIÊNCIA AÉREA DE AVIÁRIOS COM PROTÓTIPO DE BAIXO CUSTO
}

\section{CHAPTER 18. AERIAL ENVIRONMENT DIAGNOSIS OF THE POULTRY HOUSE WITH LOW COST PROTOTYPE}

\author{
Leandro Augusto de Carvalho' ${ }^{1}$ Jorge Otta Junior ${ }^{2}$; Augusto Vaghetti Luchese ${ }^{3}$, Laercio Mantovani \\ Frare $^{4}$; Pedro Luiz de Paula Filho ${ }^{5}$
}

\section{Resumo}

A ambiência aérea de aviários é um assunto que vem sendo abordado em pesquisas voltadas, tanto para o bem-estar animal, quanto para a saúde dos trabalhadores da atividade avícola. A razão motivando o desenvolvimento dessa pesquisa foi a carência de equipamentos de baixo custo, que possibilitem o diagnóstico das condições aéreas dos aviários. Para tanto, foi construído um protótipo que permitiu realizar análises em quatro dias amostrais da produção de frango de corte e apresentado um relatório resumido dos aspectos ambientais de amônia, dióxido de carbono, temperatura e umidade relativa do ar, com base em coletas contínuas realizadas durante o ciclo produtivo. Diante disso, observou-se que o aviário experimental obteve resultados dentro dos padrões ideais para criação de frango de corte, bem como das condições de trabalho salubre.

Palavras-Chaves: Avicultura, Amônia, Dióxido de carbono, Aviário.

\begin{abstract}
The air environment of poultry is a subject that has been addressed in research focused on both animal welfare and the health of poultry workers. The reason that motivated the development of this research was the lack of low cost equipments that allow the diagnosis of the aviary air condition. To this end, a prototype was built that made it possible to carry out analyzes on four sampling days of the production of broiler chicken and presented a summary report of the environmental aspects of ammonia, carbon dioxide, temperature and relative humidity, based on continuous collections carried out during the productive cycle. Therefore, it was observed that the experimental poultry house obtained results within the ideal standards for broiler rearing, as well as healthy working conditions.
\end{abstract}

Keywords: Aviculture, Ammonia, Carbon dioxide, Poultry house.

\footnotetext{
${ }^{1}$ Programa de Pós Graduação Tecnologias Computacionais para o Agronegócio, UTFPR Campus Medianeira, leandrocarvalho@utfpr.edu.br

${ }^{2}$ Programa de Pós Graduação Tecnologias Computacionais para o Agronegócio, UTFPR Campus Medianeira, jorgejunior@utfpr.edu.br

${ }^{3}$ Programa de Pós Graduação Tecnologias Computacionais para o Agronegócio, UTFPR Campus Medianeira, aluchese@utfpr.edu.br

${ }^{4}$ Programa de Pós Graduação Tecnologias Computacionais para o Agronegócio, UTFPR Campus Medianeira, laercio@utfpr.edu.br

${ }^{5}$ Programa de Pós Graduação Tecnologias Computacionais para o Agronegócio, UTFPR Campus Medianeira, pedrol@utfpr.edu.br
} 


\section{Introdução}

A avicultura é considerada uma importante atividade para a economia e desenvolvimento do agronegócio do país. De acordo com o Departamento de Agricultura dos Estados Unidos (USDA), o Brasil é o segundo maior produtor mundial de carne de frango, atrás apenas dos Estados Unidos (FRANCO, 2017).

Esse cenário se deve principalmente aos constantes ganhos de produtividade, sobretudo, através da melhoria dos índices de conversão alimentar, dos ganhos nutricionais, da pesquisa em genética, da maior automação dos aviários e de um melhor manejo (SOUSA; OSAKI, 2005).

A atividade avícola tem se destacado no campo da produção animal por ser um ciclo produtivo de curta duração, com bons retornos financeiros, exigência de pequenas áreas para implantação de granjas, entre outros motivos. Das espécies mais exploradas, destaca-se o frango, mas existe também a produção de codornas, patos, marrecos, perus, avestruzes, entre outros. A principal atividade é a produção de carne e ovos, conhecida como exploração de ave de corte e ave de postura, respectivamente (LOPES, 2011).

A cadeia produtiva de frango de corte é constituída por várias etapas interligadas entre si, que compreendem desde a produção das matrizes até o processamento e comercialização da carne industrializada. $\mathrm{O}$ aviário é um elo da cadeia produtiva e corresponde a uma etapa de produção onde se dá o crescimento e a engorda dos pintainhos, que ali chegam com algumas horas depois de nascidos, e ficam até a época de abate, aos 43 dias aproximadamente (ARAÚJO et al. 2008).

Durante esse período, as condições de alojamento devem garantir a proteção das aves, fornecendo conforto térmico com níveis apropriados de ventilação, umidade, temperatura, abrigo contra precipitação, insolação direta e segurança contra animais predadores. Um animal está em bom estado de bem-estar se estiver saudável, confortável, bem nutrido, seguro, for capaz de expressar seu comportamento inato, e se não estiver sofrendo com estados desagradáveis, tais como dor, medo e angústia (OIE, 2019).

Além disso, essas unidades devem apresentar condições de trabalho em conformidade com as normativas vigentes, preservando a saúde dos trabalhadores. Atividades de até 48 horas por semana em ambientes com concentração de 20 ppm (partes por milhão) de amônia são considerados de grau médio de insalubridade (BRASIL,1978). Portanto, para garantir as condições ideais de bem-estar animal e de segurança no trabalho, alguns fatores devem ser observados referente à ambiência aérea dos aviários. 
A concentração dos gases nos galpões está diretamente relacionada com fatores como temperatura, umidade relativa do ar, material e idade da cama aviária, tipo de ventilação, duração do ciclo de frangos e densidade de criação entre outros (OVIEDO-RONDON, 2008; OLIVEIRA; MONTEIRO, 2013).

A cama do aviário possui como principais funções reduzir o impacto e atrito da ave com o piso, absorver a umidade do galpão e diluir a matéria fecal. Geralmente são utilizados materiais como maravalha ou serragem de madeira, por ter alta disponibilidade, baixo custo e ser absorvente. É na cama do aviário onde ocorre a decomposição microbiana do nitrogênio dos dejetos dos frangos, que passa a emitir o gás amônia para o ar (ARAÚJO, 2013).

O nível de amônia ideal para criação de frango de corte deve ser inferior à 10 ppm. Taxas de concentração acima de 10 ppm podem danificar a superfície do pulmão, aumentar a suscetibilidade à doenças respiratórias, e reduzir a taxa de crescimento (ROSS, 2018; COBB, 2008). Além da amônia, existem outros contaminantes do ar como poeira, excesso de vapor de água e gases como dióxido de carbono e monóxido de carbono, igualmente prejudiciais quando em níveis elevados.

Os fatores térmicos como temperatura do ar, umidade, radiação térmica e movimentação do ar afetam mais diretamente a ave, pois comprometem sua função vital mais importante: a manutenção da própria homeotermia (TINOCO, 2001). Dessa forma, alguns equipamentos básicos para a criação das aves são requeridos como exaustores, nebulizadores e aquecedores.

Muitos dos equipamentos utilizados nos aviários são automatizados por meio de sensoriamento e programação pré-definida. Por exemplo, para acionamento dos sistemas de ventilação e aquecimento são utilizados sensores de temperatura e umidade conectados a uma unidade central. Da mesma forma, o sistema de reabastecimento da linha de comedouro é acionado por sensores nos pratos dos comedouros. Também são empregados temporizadores que controlam a iluminação.

Com relação ao monitoramento dos níveis de gases, existem equipamentos para medição e controle de gases, de uso geral que podem ser aplicados na avicultura, além de alguns sensores específicos para avicultura que podem ser interligados às centrais de automação dos aviários. O inconveniente destes sensores está relacionado ao alto investimento, o que inviabiliza este controle à pequenos produtores. Com intuito de suprir esta lacuna, o objetivo principal desse estudo consiste no desenvolvimento de um protótipo de baixo custo, capaz de fornecer ao avicultor, o diagnóstico da ambiência aérea dos aviários, fornecendo informações de temperatura, umidade, concentração de amônia e de dióxido de carbono. 


\section{Material e Métodos}

O protótipo utilizado nesse estudo, responsável por detectar as concentrações de amônia, dióxido de carbono, temperatura e umidade, foi construído utilizando placa de prototipagem e sensores de baixo custo. Os sensores de amônia modelo MQ-135, de dióxido de carbono, MG-811, e, de temperatura e umidade do ar, BME280, possuem preços acessíveis e são encontrados em lojas especializadas.

De maneira geral, o funcionamento do sistema consiste em 3 etapas: coleta dos dados pelos sensores, envio das informações utilizando a rede sem fio para um servidor de dados, e processamento desses dados para exibição em forma de gráficos e análise estatística. A Figura 1 ilustra os componentes necessários e interação entre eles.

Figura 1. Diagrama dos componentes do sistema

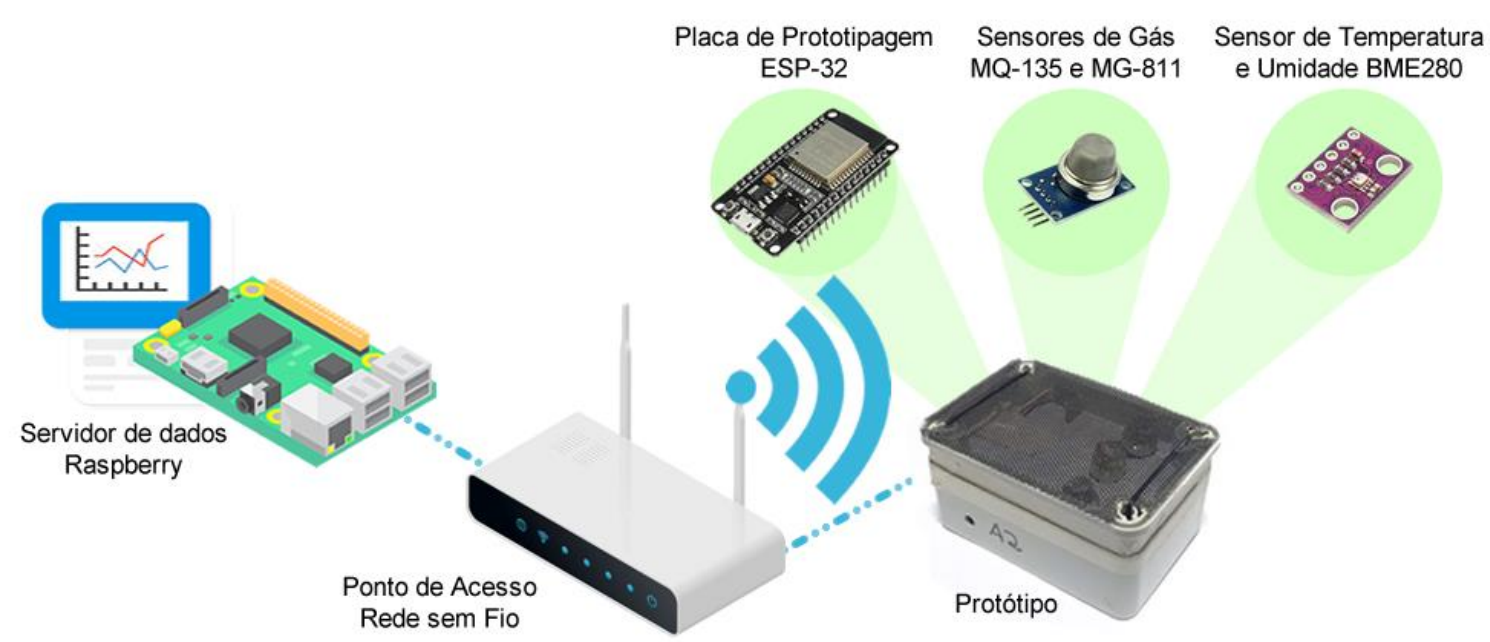

Fonte: Própria (2020).

Esses sensores são conectados nas portas de entrada e saída de sinal da placa de prototipagem ESP32, permitindo a leitura dos valores pelo software que é executado pelo microprocessador da placa. A placa de prototipagem ESP32 possui 34 portas programáveis, conexão com rede sem fio e Bluetooth, além de permitir o desenvolvimento de software utilizando esses e outros recursos disponíveis pela placa. Além da coleta, a placa de prototipagem realiza o tratamento dos dados dos módulos sensores, conexão na rede sem fio e encaminhamento dos dados para o servidor.

Para a função de servidor de armazenamento dos dados, foi utilizado um computador de placa única, Raspberry PI 3 modelo B. Esse computador também possui um valor acessível, assim como os demais componentes, além de outros recursos como a possibilidade de instalação de sistema operacional e serviços. 
Para desenvolver o relatório de diagnóstico da ambiência aérea dos aviários, foi preciso integrar um sistema informatizado de painéis de monitoramento chamado ThingsBoard. Esse sistema permite realizar a comunicação entre o servidor e o protótipo, além de fornecer recursos gráficos para exibição dos dados.

Todos os componentes do protótipo, placa de prototipagem e sensores, foram acondicionados em uma caixa de montagem, com tela perfurada permitindo a exposição dos sensores, mas protegendo os componentes contra ações externas, conforme apresentado na Figura 2.

Figura 2. Protótipo montado com a tela de proteção.

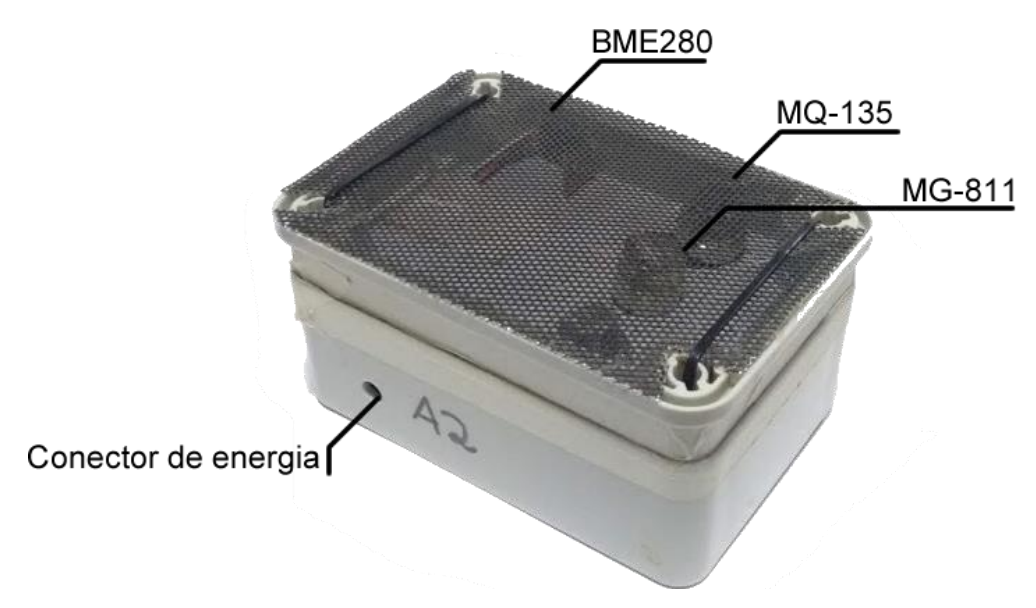

Fonte: Própria (2020).

A Tabela 1 apresenta os custos aproximados dos materiais utilizados para confecção do protótipo. Todos esses valores estão em Reais $(\mathrm{R} \$)$ e foram baseados na data da compra em Abril de 2018.

Tabela 1. Custos aproximados dos materiais do protótipo

\begin{tabular}{ll}
\hline Material & Valor $(\mathrm{R} \$)$ \\
\hline Placa de desenvolvimento ESP-32 & 57,04 \\
Sensor de gás amônia MQ-135 & 25,76 \\
Sensor de gás dióxido de carbono MG-811 & 109,87 \\
Sensor de temperatura e umidade BME-280 & 41,40 \\
Caixa para montagem & 29,90 \\
Total & $\mathrm{R} \$ 263,97$ \\
\hline
\end{tabular}
Fonte: Própria (2020).

O custo aproximado para aquisição dos materiais para produção de um protótipo foi de R\$263,97. Ainda houve o investimento no servidor de monitoramento (Raspberry), acrescendo $\mathrm{R} \$ 277,84$ ao valor total da solução. Sendo assim, pode-se afirmar que para realizar esse estudo foram despendidos $\mathrm{R} \$ 541,81$ para aquisição de materiais e equipamentos. 
As coletas foram realizadas em granja comercial de frango de corte localizada no município de Cascavel - PR, no distrito de Sede Alvorada, na Mesorregião Oeste Paranaense, latitude $24^{\circ} 49^{\prime} 36^{\prime \prime} \mathrm{S}$ e longitude $53^{\circ} 40^{\prime} 17^{\prime \prime} \mathrm{O}$, no $6^{\circ}, 8^{\circ}, 9^{\circ}$ e $12^{\circ}$ dia de alojamento dos frangos, entre os dias 02 e 08 de abril de 2019.

As condições meteorológicas características de Cascavel - PR em abril são temperaturas máximas entre $26{ }^{\circ} \mathrm{C}$ a $23{ }^{\circ} \mathrm{C}$, raramente caindo abaixo de $18{ }^{\circ} \mathrm{C}$ ou ultrapassando $30{ }^{\circ} \mathrm{C}$. As temperaturas mínimas em torno de $15{ }^{\circ} \mathrm{C}$ a $12{ }^{\circ} \mathrm{C}$, raramente caindo abaixo de $7{ }^{\circ} \mathrm{C}$ ou ultrapassando $18{ }^{\circ} \mathrm{C}$. A probabilidade de um dia com precipitação ao longo de abril decresce gradualmente, começando o mês com 38\% e terminando com 36\% (WEATHERSPARK, 2020).

As coletas foram realizadas em aviário com área de $1.200 \mathrm{~m}^{2}$, com pé-direito de 2,2 metros e pilares de concreto a cada 3 metros, com tesouras de madeiras e cobertura de telhas de barro. O sistema de ventilação era do tipo túnel de vento com pressão negativa, possuía um grupo de seis exaustores, com seis pás de 53 polegadas e motor de 1,5 cv. A alimentação das aves era realizada por três linhas de comedouro e quatro linhas de bebedouro do tipo nipple. Para manter o aviário aquecido, foram utilizados dois aquecedores à lenha. Todos os sistemas de ventilação, aquecimento, iluminação e abastecimento de água e ração eram automatizados.

Durante os dias experimentais, o protótipo permaneceu instalado no mesmo local, à 15 $\mathrm{m}$ da parede da entrada do aviário, e $3 \mathrm{~m}$ da parede lateral, junto ao solo. A Figura 3 mostra um croqui do aviário e a posição do protótipo.

Figura 3. Croqui do aviário.

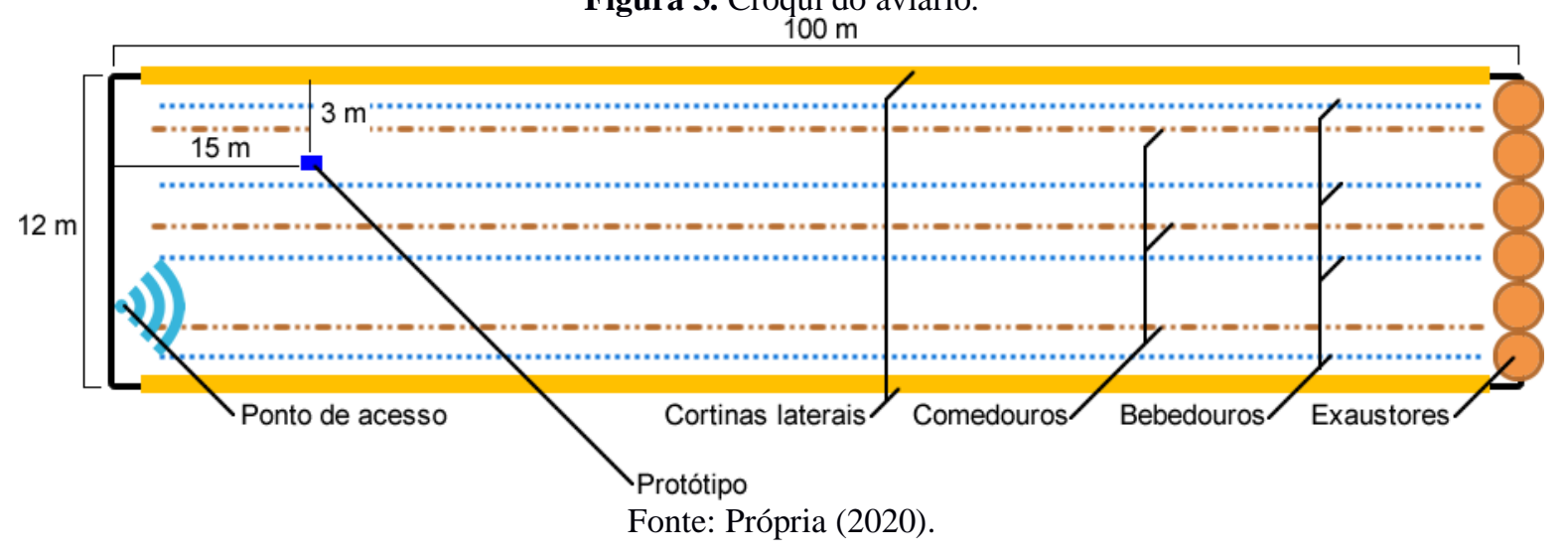

A rotina de coleta e envio dos dados ao servidor de monitoramento era feita de minuto a minuto. Após o período experimental, os dados foram organizados pela média, em grupos de quinze minutos de coleta. Para facilitar a apresentação e interpretação dos dados, gráficos de dispersão, diagramas de frequência, boxplots, e estatística descritiva foram empregados. Para 
análise da variância dos tratamentos foi utilizada a distribuição F de Snedecor, e o teste de Tukey de comparações múltiplas.

\section{Resultados e Discussão}

As coletas registradas pelo sensor MQ-135 referente às concentrações de amônia são apresentadas na Figura 4. Observa-se que a todas as leituras ficaram entre 4 e 7 ppm. Com a estatística descritiva dos dados coletados, foi possível identificar que as médias das concentrações de amônia diminuíram conforme aumenta a idade dos frangos. O mesmo acontece para a mediana e para os valores mínimos detectados.

Os gráficos de séries temporais apresentam lacunas, devido a falhas no momento da leitura dos sensores, por instabilidades na rede elétrica do aviário. O eixo X representa o período do dia em que foi realizada a leitura do sensor, e o eixo Y apresenta a concentração de amônia em ppm.

Figura 4. Concentração de amônia quantificada pelo sensor MQ-135 no período amostral.

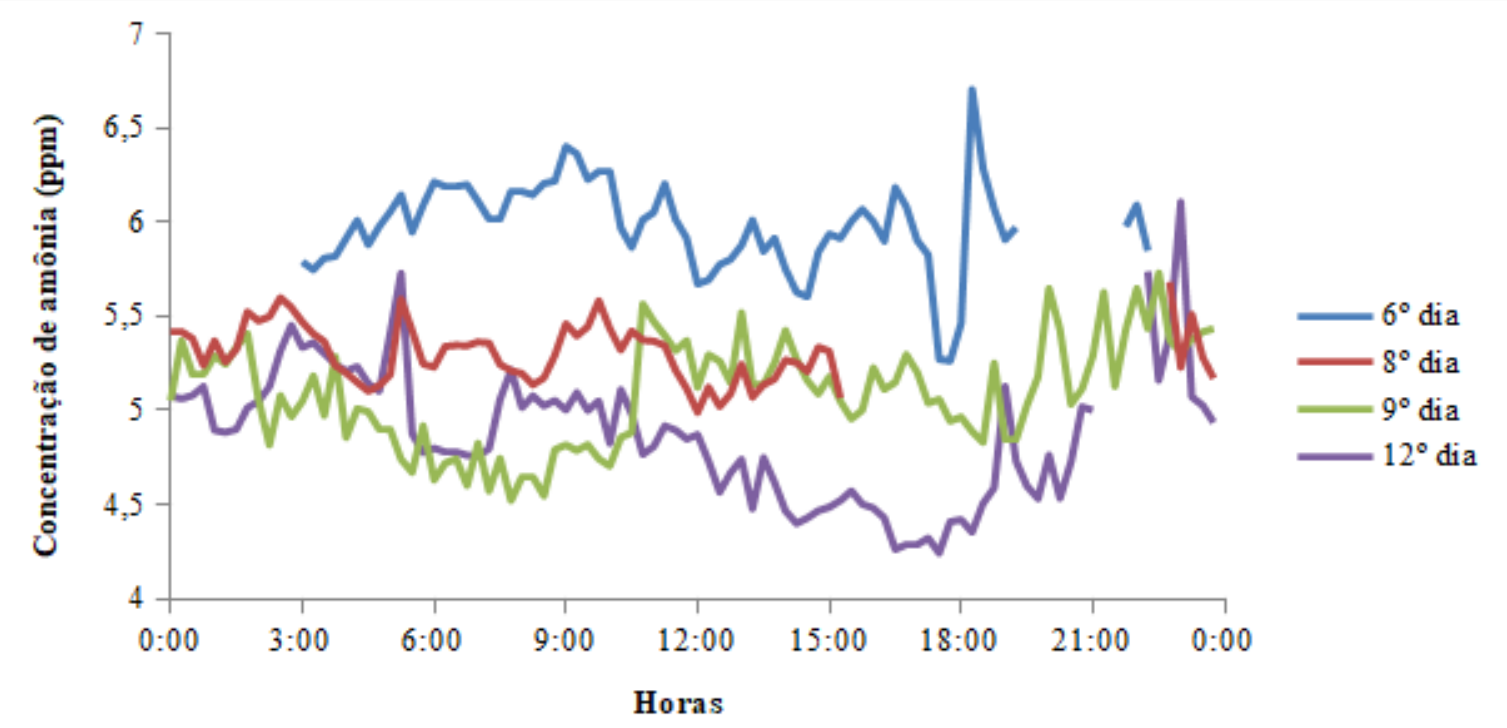

Fonte: Própria (2020).

Uma explicação para esse fenômeno pode ser o fato da ventilação se tornar mais constante conforme o desenvolvimento dos frangos, fazendo com que ocorra a troca de ar com mais frequência, diminuindo a concentração de amônia.

Todas as amostras obtiveram valores inferiores a $10 \mathrm{ppm}$. Sendo assim, o aviário apresentou condições ideais para a criação de frango de corte e limites toleráveis de insalubridade para os trabalhadores dessa unidade. 
A Figura 5 apresenta os diagramas de frequência dos quatro dias observados, referente as concentrações de amônia. Todos os tratamentos apresentaram p-valor > 0,05 no teste Kolmogorov-Smirnov (KS), indicando que não há evidências suficientes para concluir que os dados não seguem uma distribuição normal.

Figura 5. Diagramas de frequência das concentrações de amônia
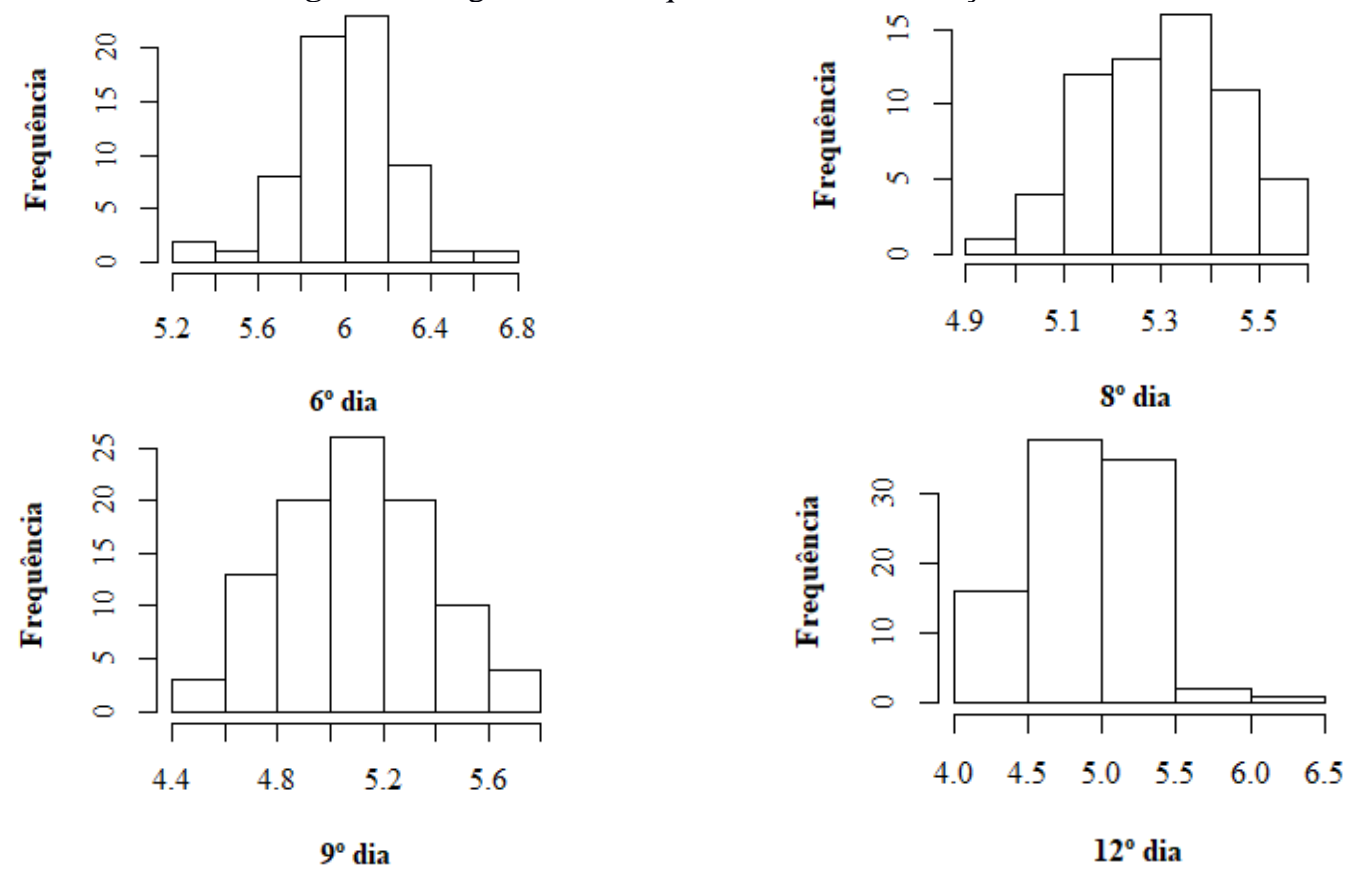

Fonte: Própria (2020).

Para identificar pontos discrepantes nas amostras, foram produzidos os boxplots, mostrados na Figura 6 com as leituras do sensor MQ-135 nos dias observados. O $8^{\circ}$ e o $9^{\circ}$ dia tiveram um comportamento semelhante, não apresentando outliers. Já o $6^{\circ}$ e $012^{\circ}$ dia apresentaram outliers em suas amostras. Em relação a variabilidade dos dados, o $9^{\circ}$ e $12^{\circ}$ dia apresentaram maior variabilidade comparando com os demais dias amostrais. Os níveis médios de amônia são decrescentes do $6^{\circ}$ ao $12^{\circ}$ dia.

Com a distribuição F de Snedecor, foi possível verificar que existe pelo menos um contraste entre as médias dos tratamentos, ao nível de 5\% de probabilidade. Ou seja, existe diferença entre as médias de concentração de amônia, entre os dias em que foram realizadas as coletas de dados.

Realizando o teste de Tukey de comparações múltiplas, observou-se que todas as médias dos tratamentos possuem diferenças entre si, a nível de 5\% de significância. Ou seja, há evidências de que as médias de concentrações de amônia variam conforme o período de alojamento. 
Figura 6. Boxplots das concentrações de amônia (ppm) dos dias observados.

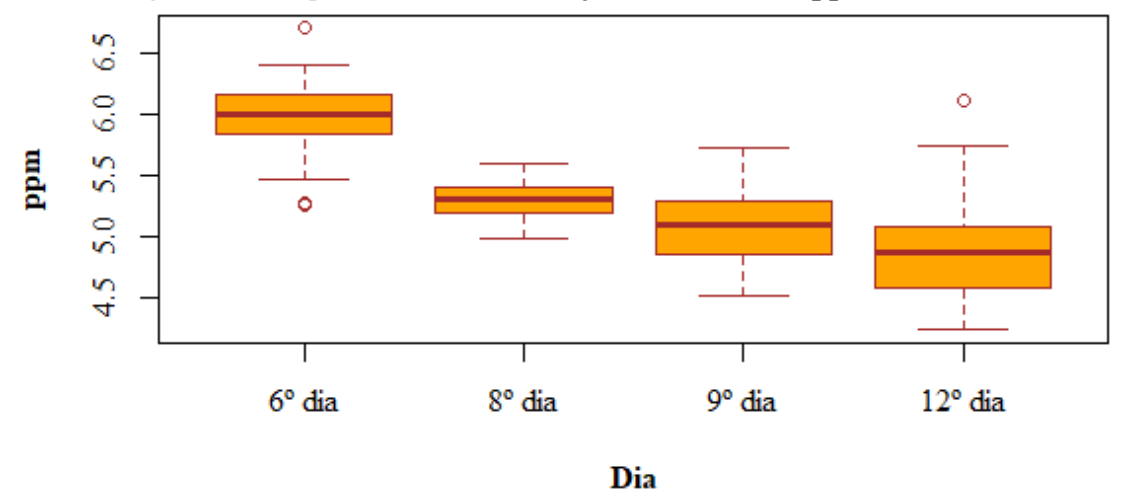

Fonte: Própria (2020).

As concentrações de dióxido de carbono foram detectadas pelo sensor MG-811, e estão apresentadas no gráfico de séries temporais da Figura 7. Por meio da análise gráfica não foi identificada uma tendência entre as séries de dados.

Figura 7. Concentração de dióxido de carbono quantificada pelo sensor MG-811 no período amostral.

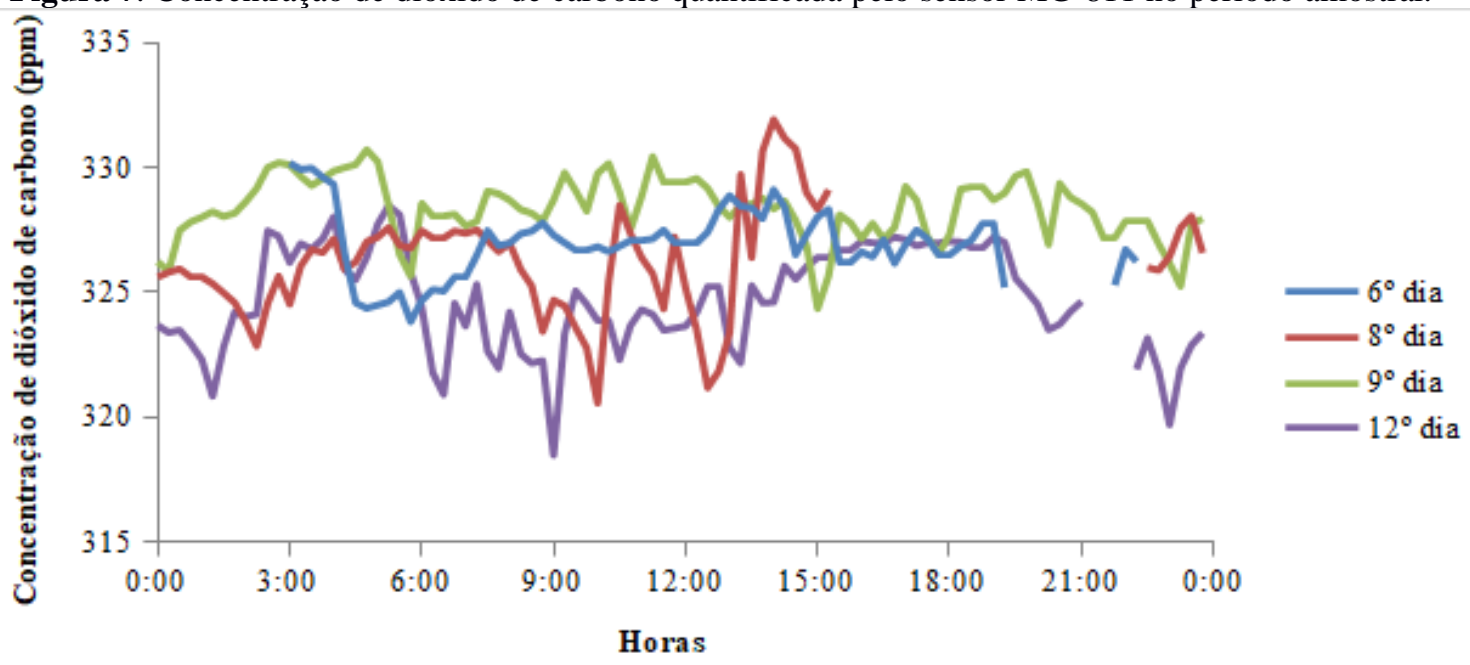

Fonte: Própria (2020).

A estatística descritiva dos dados coletados, evidenciou que as médias de concentração de dióxido de carbono variaram menos de 4 ppm entre os dias estudados, e não seguiram a tendência observada na concentração de amônia, de redução conforme a idade das aves.

A concentração mínima detectada foi de 318 ppm e a máxima de 331 ppm, dentro do nível considerado ideal para criação de frango de corte, que é inferior à 3.000 ppm. Atividades em ambientes com concentrações de dióxido de carbono acima de 3.900 ppm são consideradas insalubres, portanto, não se verificou essa condição no aviário experimental. 
A Figura 8 mostra os diagramas de frequência dos quatro dias observados, referente as concentrações de dióxido de carbono (ppm). Utilizando o teste $\mathrm{KS}$, apenas os dados do $12^{\circ}$ dia apresentaram p-valor maior que 0,05 . Ou seja, não há evidências suficientes para concluir que os dados não seguem normalidade apenas para a amostra do $12^{\circ}$ dia.

Figura 8. Diagramas de frequência das concentrações de dióxido de carbono
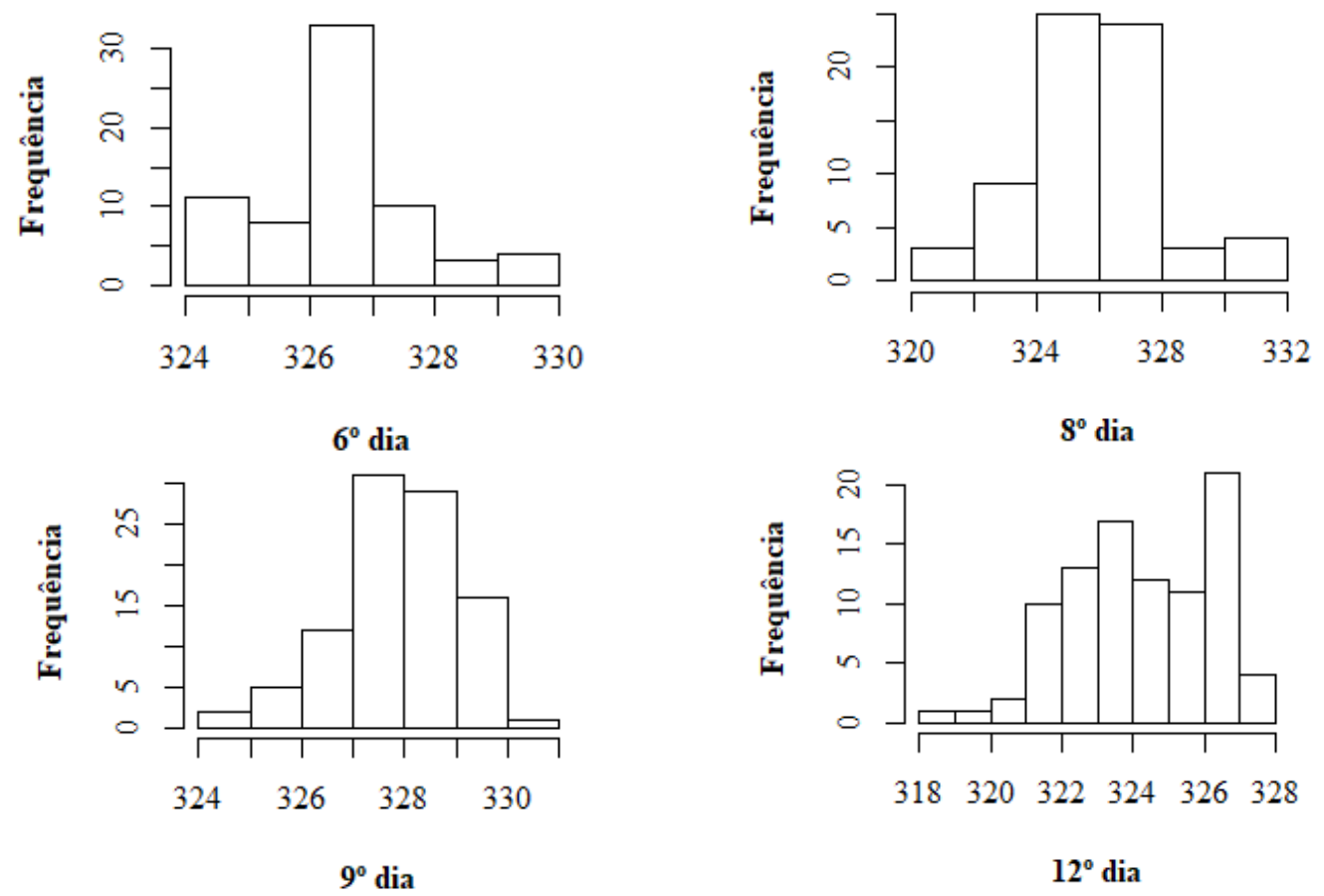

Fonte: Própria (2020).

Com auxílio do boxplot da Figura 9, é possível identificar pontos discrepantes nas amostras do $6^{\circ}, 8^{\circ}$ e $9^{\circ}$. Apenas o $12^{\circ}$ não apresentou outlier em seu conjunto de dados. As maiores variabilidades são observadas no $8^{\circ}$ e $12^{\circ}$ dia. Os níveis médios de dióxido de carbono são próximos, variando em torno de 325 ppm à 328 ppm.

Figura 9. Boxplots das concentrações de dióxido de carbono (ppm) dos dias observados.

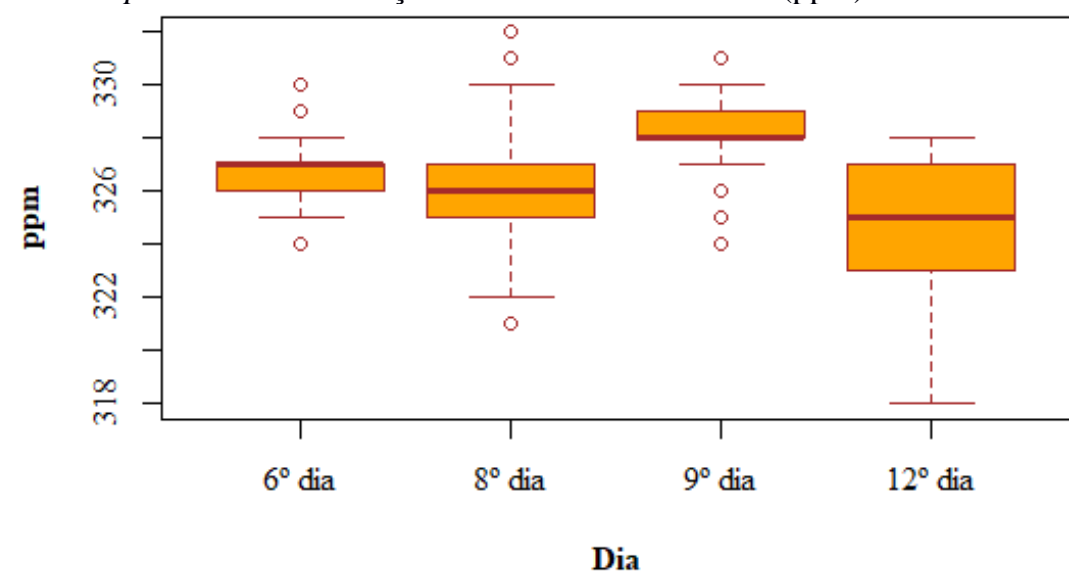

Fonte: Própria (2020).

[266]

CIÊNCIA, TECNOLOGIA E INOVAÇÃO: DO CAMPO À MESA. RECIFE: EDITORA IIDV, 2020 
Verificou-se que pelo menos uma média dos tratamentos se diferencia das demais, utilizando a distribuição F de Snedecor, ao nível de 5\% de probabilidade, e utilizando o teste de Tukey de comparações múltiplas, observou-se que o $6^{\circ}$ e $8^{\circ}$ dia não apresentaram diferenças significativas em suas médias de concentrações. Ou seja, há evidências de que as concentrações de dióxido de carbono não apresentaram variações significativas estatisticamente, em determinados períodos de alojamento.

Os dados de temperatura e umidade do ar foram coletados com o sensor modelo BME280. Esse sensor mostrou-se eficiente pelo tempo de resposta das leituras e número reduzido de falhas em relação a outros sensores testados. As coletas de temperatura são apresentadas na Figura 10.

Figura 10. Temperatura ambiente $\left({ }^{\circ} \mathrm{C}\right)$ quantificada pelo sensor BME280 no período amostral.

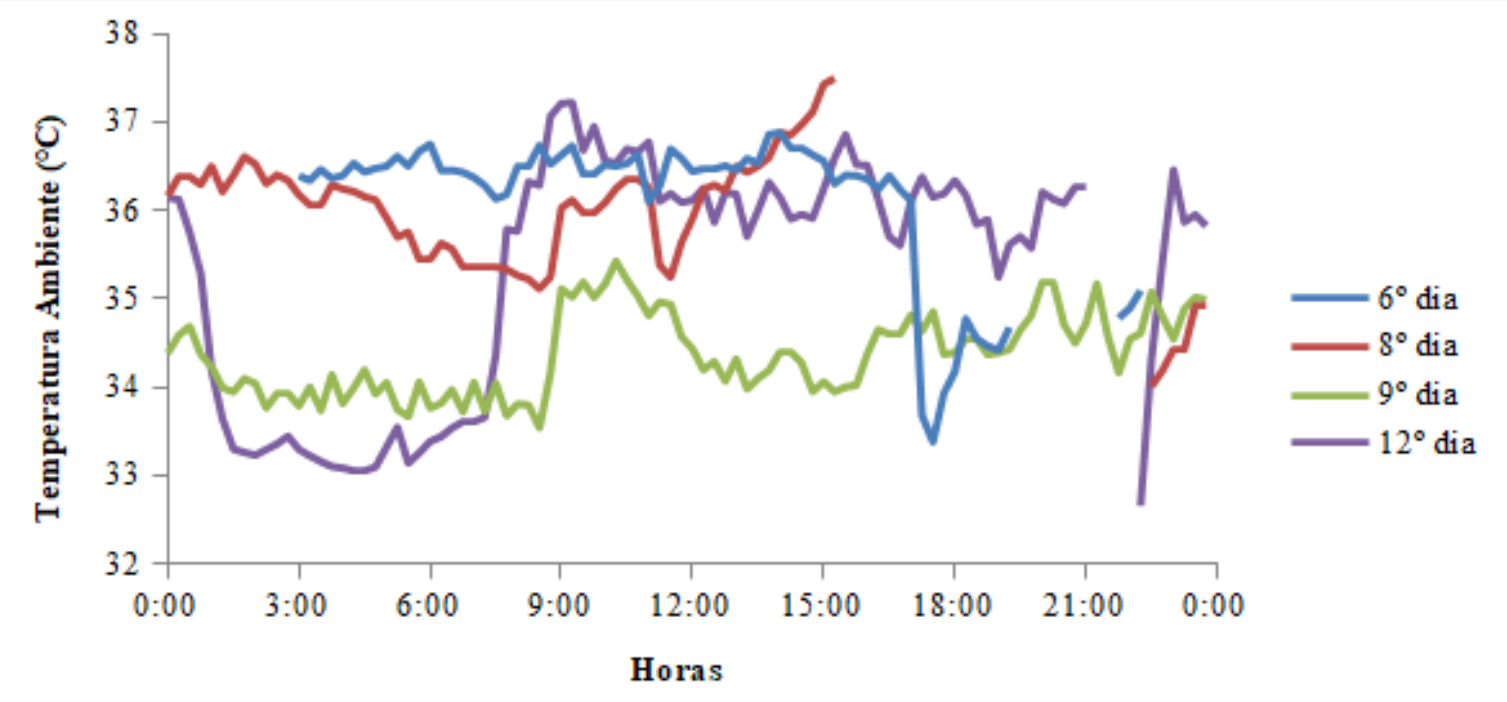

Fonte: Própria (2020).

Nessa representação gráfica é possível observar que no $6^{\circ}$ dia, a temperatura mantevese entre $36{ }^{\circ} \mathrm{C}$ e $37{ }^{\circ} \mathrm{C}$ até as $17 \mathrm{~h}$, mostrando um comportamento de estabilidade em relação aos demais dias. Isso pode ser explicado, pois, nos dias iniciais do lote produtivo, a ventilação é mínima para evitar choques de temperatura e favorecer o desenvolvimento saudável das aves. Nos demais dias experimentais, observa-se que a variação de temperatura é maior com o passar do tempo.

Com a estatística descritiva, foi possível observar que a média de temperatura foi decrescente entre o $6^{\circ}$ e $9^{\circ}$ dia. No $12^{\circ}$ dia a média sofreu aumento de $1^{\circ} \mathrm{C}$ em relação ao $9^{\circ}$ dia. 
Isso ocorre devido a ventilação mínima ser suspensa a partir do $10^{\circ}$ dia de alojamento. A Figura 12 apresenta os diagramas de frequência das temperaturas observadas.

Figura 12. Diagramas de frequência das temperaturas
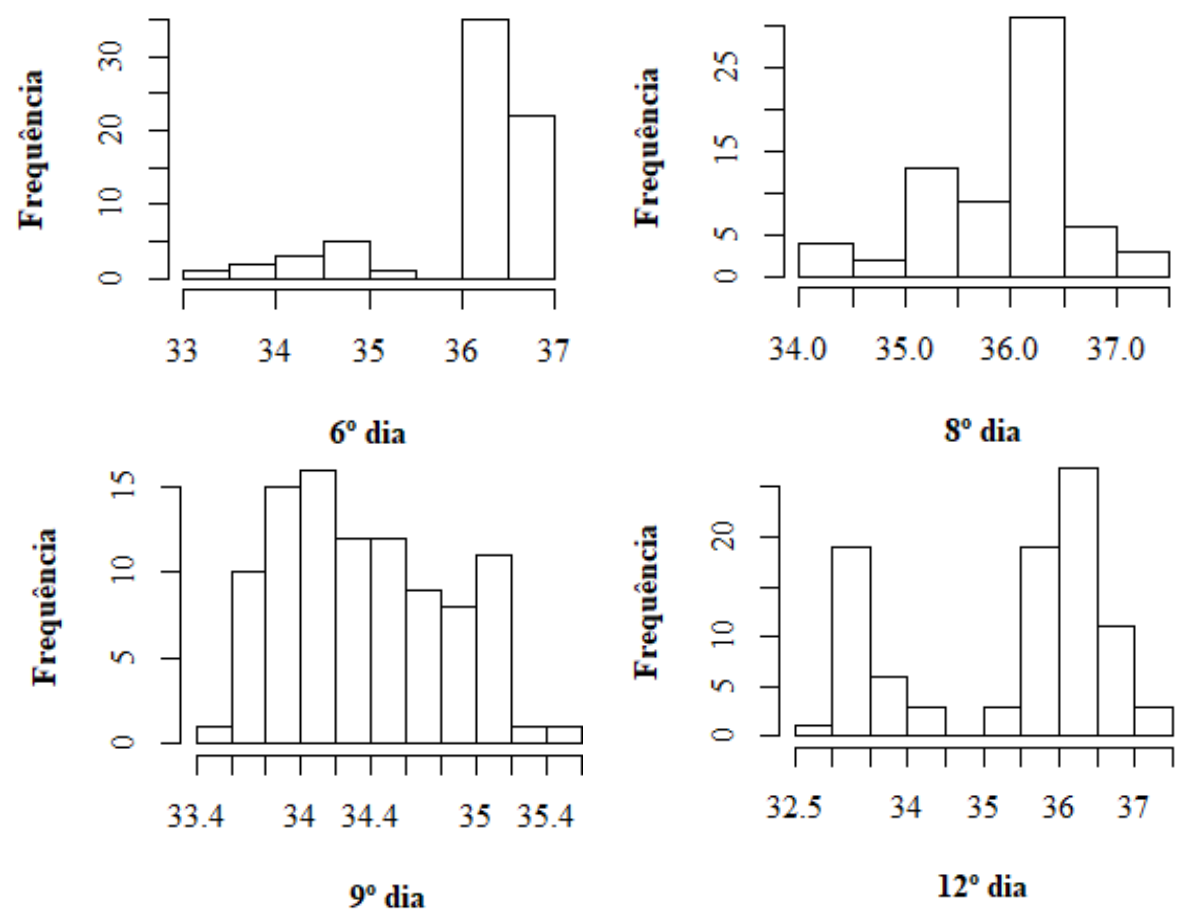

Fonte: Própria (2020).

Os dados do $6^{\circ}$ e $12^{\circ}$ apresentaram p-valor menor do que 0,05 no teste KS, logo, essas amostras não seguem uma distribuição normal. O boxplot da Figura 13 mostra que apenas os dados do $6^{\circ}$ dia apresentaram pontos discrepantes. Esses pontos discrepantes foram localizados em uma sequência de leituras no $6^{\circ}$ dia a partir das $17 \mathrm{~h}$, indicando um possível incidente no sistema de aquecimento, considerando a queda repentina na temperatura do ambiente. Os valores médios da temperatura foram decrescentes até o $9^{\circ}$ dia.

Utilizando a distribuição F de Snedecor, foi possível identificar que pelo menos um dos tratamentos apresenta diferença em relação aos demais, ao nível de 5\% de probabilidade. Com o teste de Tukey de comparações múltiplas, observou-se que o $6^{\circ}$ e $8^{\circ}$ dia não apresentaram diferenças significativas em suas médias de temperatura. Ou seja, há evidências de que as temperaturas não apresentam diferenças significativas nos períodos iniciais de alojamento.

Quanto à umidade relativa do ar, os dados são apresentados na Figura 14, e observa-se que os valores do $6^{\circ}$ e $12^{\circ}$ dia são inferiores, variando na maior parte do dia entre $50 \%$ e $55 \%$ no $6^{\circ}$ dia, e entre $50 \%$ e $60 \%$ no $12^{\circ}$ dia.

A estatística descritiva desses dados revelou que a média da umidade relativa aumentou 
até o $9^{\circ}$ dia, variando entre $54 \%$ e $61 \%$ e no $12^{\circ}$ dia, a média foi de $56 \%$.

Figura 13. Boxplots das temperaturas (Celsius) dos dias observados.

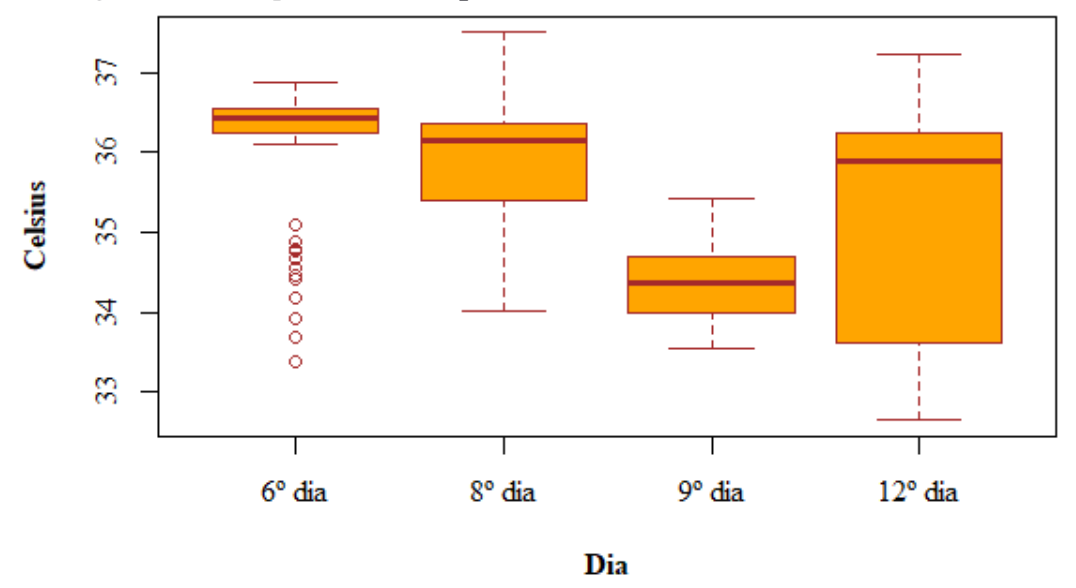

Fonte: Própria (2020).

Figura 14. Umidade relativa do ar (\%) quantificada pelo sensor BME-280 no período amostral.

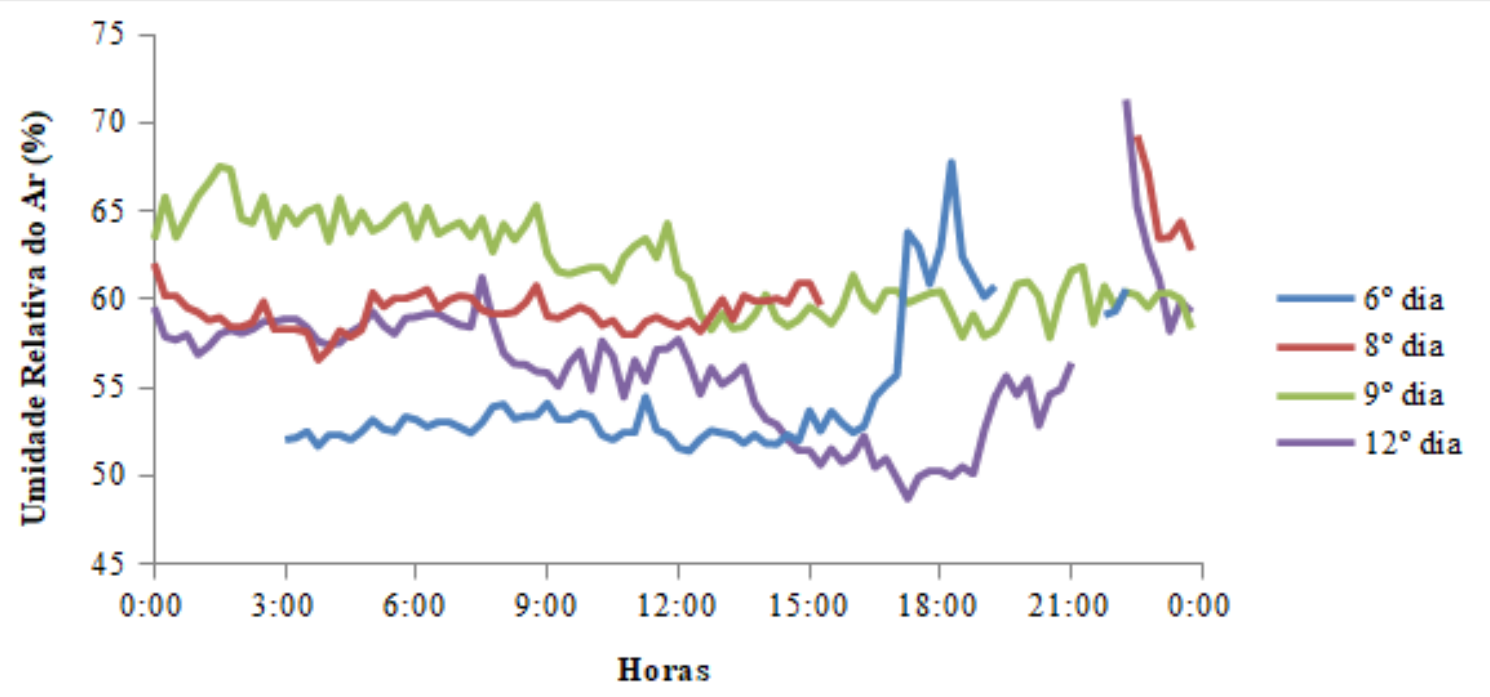

Fonte: Própria (2020).

Os valores mínimos variaram de $48 \%$ a 57\%, e máximos de $67 \%$ a $71 \%$. O nível ideal de umidade do ar é entre $50 \%$ e $60 \%$, e, em alguns momentos dos dias estudados, as incidências ultrapassaram esses limites. Os diagramas de frequência da Figura 15 mostram que os dados não apresentaram normalidade.

Sobre pontos discrepantes, a Figura 16 apresenta o boxplot onde apenas no $9^{\circ}$ dia não foram detectados outliers nas amostras. As amostras apresentam uma tendência crescente da variabilidade dos dados conforme os dias de alojamento. Os valores médios foram crescentes até o $9^{\circ}$ dia. 
Figura 15. Diagramas de frequência das umidades relativa do ar.
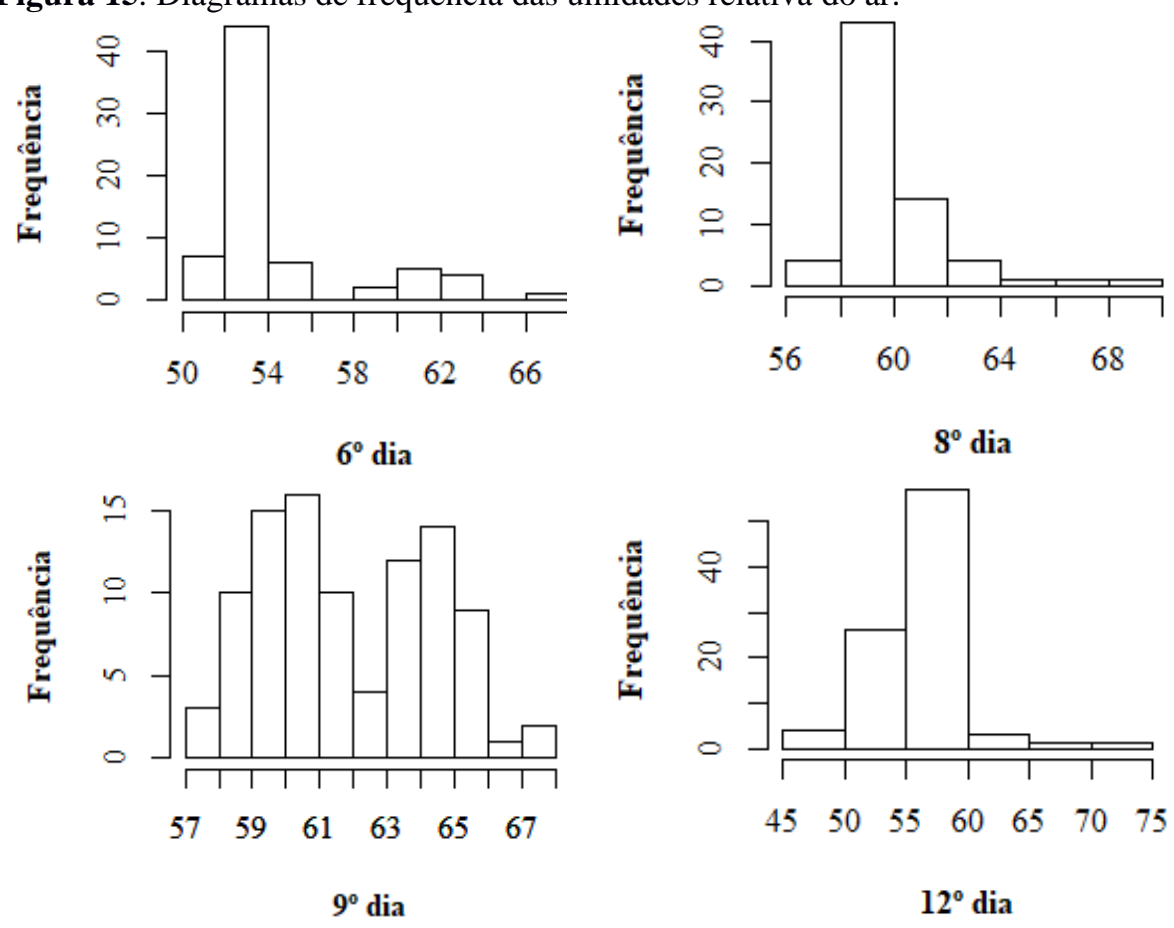

Fonte: Própria (2020).

Figura 16. Boxplots das umidades relativa do ar $(\%)$ dos dias observados.

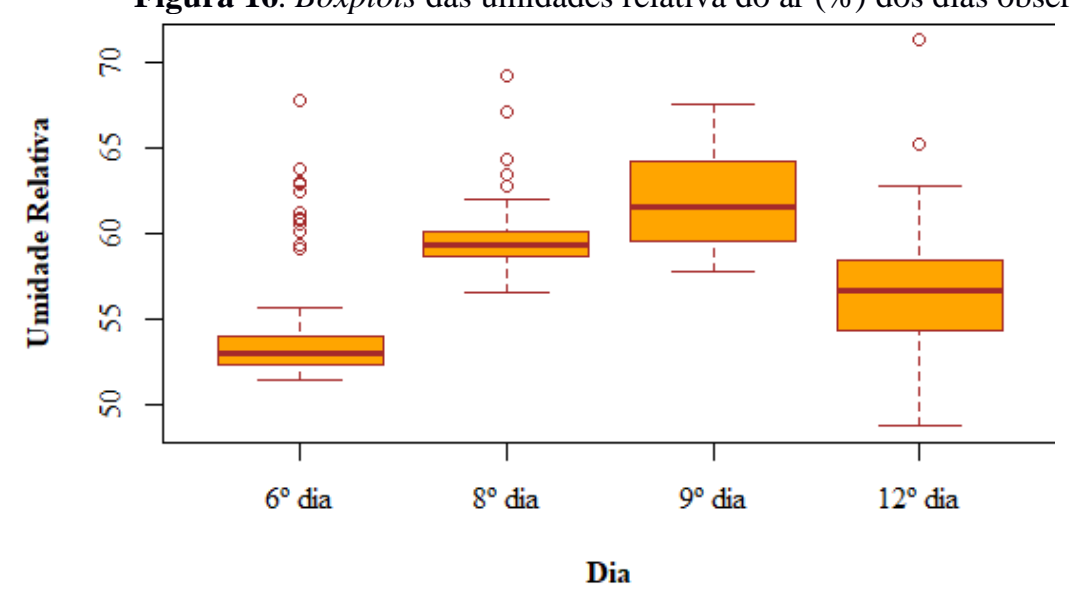

Fonte: Própria (2020).

Com a distribuição F de Snedecor, evidenciou-se que pelo menos um dos tratamentos apresenta diferença em relação aos demais, ao nível de 5\% de probabilidade. O teste de Tukey de comparações múltiplas, mostrou que todos os tratamentos possuem diferenças significativas em suas médias de umidade relativa do ar. Sendo assim, pode-se afirmar que, a umidade relativa do ar apresenta variações significativas estatisticamente, nos períodos de alojamento observados. 
Os valores mínimos variaram de $48 \%$ a 57\%, e máximos de $67 \%$ a $71 \%$. O nível ideal de umidade do ar é entre 50\% e 60\%, e, em alguns momentos dos dias estudados, as incidências ultrapassaram esses limites.

\section{Conclusões}

Com o desenvolvimento desse estudo, o avicultor pode observar de maneira contínua, o controle da ambiência aérea do aviário. Os níveis de concentração de amônia e dióxido de carbono detectados estão dentro dos limites aceitáveis de qualidade do ar para criação de frango de corte, e dos limites toleráveis de insalubridade para os trabalhadores.

As análises estatísticas evidenciaram que em determinados dias, alguns fatores ambientais observados não apresentaram diferenças significativas nas médias. Foi o caso das concentrações de dióxido de carbono e da temperatura do ar, no $6^{\circ}$ e $8^{\circ}$ dia. Isso denota que o aviário em questão possui um sistema de automação eficiente capaz de manter o ambiente controlado.

A concentração de gases no aviário durante o período em que foram realizados os testes, não atingiu valores elevados. Porém, o mesmo protótipo pode ser utilizado em outros ambientes onde pode haver alta concentração de gases, como em frigoríficos, onde o gás amônia é muito utilizado nos sistemas de refrigeração e eventualmente acontecem vazamentos, ou em espaços confinados onde há o acúmulo de gases tóxicos.

\section{Referências}

ARAÚJO, F. G. Bem-estar e Ambiência das Aves. Urutaí,: IFGO, 2013. 102 p. Disponível em:

http://proedu.rnp.br/bitstream/handle/123456789/1471/Bem_Estar_e_Amb_das_Aves_WEB. pdf. Acesso em: 14 ago. 2020.

ARAÚJO, G. C.; BUENO, M. P.; BUENO, V. P.; SPROESSER, R. L.; SOUZA, I. F. Cadeia produtiva da avicultura de corte: avaliação da apropriação de valor bruto nas transações econômicas dos agentes envolvidos. Gestão \& Regionalidade, São Caetano do Sul, v. 24, n. 72, p. 6-16, $\quad$ set./dez. 2008. Disponível https://seer.uscs.edu.br/index.php/revista_gestao/article/view/95/58. Acesso em: 14 ago. 2020.

BRASIL. Ministério do Trabalho e Emprego. NR 15 - Atividade e operações insalubres. Brasília: Ministério do Trabalho e Emprego, 1978. Disponível em: https://enit.trabalho.gov.br/portal/images/Arquivos_SST/SST_NR/NR-15-atualizada2019.pdf. Acesso em: 14 ago. 2020.

COBB. Manual de Manejo de Frangos de Corte. 2008. Disponível em: https://wp.ufpel.edu.br/avicultura/files/2012/04/Cobb-Manual-Frango-Corte-BR.pdf. Acesso em: 15 ago. 2020. 
FRANCO, A. S. M. A avicultura no Brasil. Análise conjuntural. 2017. Curitiba, PR. v.39, n.1-2/jan./fev. Disponível em: http://www.ipardes.gov.br/biblioteca/docs/bol_39_1_c.pdf. Acesso em: 14 ago. 2020.

LOPES, J. C. O. Técnico em avicultura. Floriano: Edufpi, 2011. 94 p. Disponível em: http://pronatec.ifpr.edu.br/wp-content/uploads/2013/06/Avicultura.pdf. Acesso em: 14 ago. 2020.

OIE. World Organisation for Animal Health, Terrestrial Animal Health Code. Disponível em https://www.oie.int/standard-setting/terrestrial-code/access-online. Acesso em: 14 ago. 2020.

OLIVEIRA, P. A. V.; MONTEIRO, A. N. T. R. Emissão de amônia na produção de frangos de corte. In: CONFERÊNCIA FACTA, Campinas, 2013. Anais. Campinas: Facta, 2013. 1 CDROM.

http://ainfo.cnptia.embrapa.br/digital/bitstream/item/91032/1/final7197.pdf. Acesso em: 14 ago. 2020.

OVIEDO-RONDON, E. O. Tecnologias para mitigar o impacto ambiental da produção de frangos de corte. R. Bras. Zootec., Viçosa, v. 37, n. spe, p. 239-252, Julho 2008. DOI: https://doi.org/10.1590/S1516-35982008001300028.

Disponível

em:

http://www.scielo.br/scielo. Acesso em: 03 ago. 2020.

ROSS. Manual De Manejo De Frangos Ross. 2018. Disponível em: https://en.aviagen.com/assets/Tech_Center/Ross_Broiler/Ross-BroilerHandbook2018-EN.pdf. Acesso em: 14 ago. 2020.

SOUSA, D. P.; OSAKI, M. Caracterização do Mercado Internacional de Carne de Frango Brasil X Estados Unidos. In: XLIII Congresso de Sociedade Brasileira de Economia, Adminsitração e Sociologia Rural, 2005, Ribeirão Preto. Disponível em: https://www.cepea.esalq.usp.br/br/documentos/texto/artigo-publicado-no-xliii-congresso-dasober-caracterizacao-do-mercado-internacional-de-carne-de-frango-brasil-x-estadosunidos.aspx. Acesso em: 14 ago. 2020.

TINOCO, I. F. F. Avicultura Industrial: Novos Conceitos de Materiais, Concepções e Técnicas Construtivas Disponíveis para Galpões Avícolas Brasileiros. Rev. Bras. Cienc. Avic., Campinas, v. 3, n. 1, p. 01-26, Janeiro 2001. DOI: https://doi.org/10.1590/S1516635X2001000100001. Disponível em: http://www.scielo.br/scielo. Acesso em: 03 agosto 2020.

WEATHERSPARK. Condições meteorológicas características de Cascavel em abril. Disponível em: https://pt.weatherspark.com/m/29585/4/Condições-meteorológicascaracterísticas-de-Cascavel-Brasil-em-abril. Acesso em: 14 ago. 2020. 